\title{
Knowledge, attitude and Behavior of the Moroccan Population During Covid-19
}

\author{
Soumaia Hmimou $^{1}$, Nesma Nekkal ${ }^{2}$, Youssef Azami Idrissi ${ }^{1}$, Sara Boukhorb ${ }^{1}$, Khaoula Bendahbia ${ }^{1}$, \\ Sidi Mohamed Riad Benzidane ${ }^{2}$, Abdelmajid Soulaymani ${ }^{1}$ \\ ${ }^{1}$ Ibn Tofail University, Faculty of Science, Kenitra, Morocco, ${ }^{2}$ Center of Biological and Medical Sciences, CIAM, \\ Mohamed VI Polytechnic University, Ben-Guerir, Morocco
}

\begin{abstract}
Background: Since December 2019 the world has experienced a significant spread of the Covid-19 pandemic. The purpose of this study is to investigate the impact of the coronavirus disease (COVID-19) on the mental health of the population.

Method: This cross-sectional study was conducted in Morocco and was administered to a sample of 702 respondents. The subject was assessed using a questionnaire containing the following information: Personal demographic characteristics, knowledge and awareness of COVID-19 outbreak, Attitude towards COVID-19 outbreak, Behavioral change in relation to COVID-19 outbreak, Patient Health Questionnaire (PHQ-4) screening questions for anxiety and depression, and finally a questionnaire related to people at risk of psychological harm from social isolation during the COVID-19 pandemic, data collection began three weeks after confinement began and lasted for five weeks, from April 10 to 08 Mai.

Results: 702 participants responded to the survey. The descriptive analysis of the database showed that the majority of respondents were male $(69.3 \%)$, aged 20 to 30 years $(46.15 \%)$, with university diploma $(61.25 \%)$ and employed (63.53\%).Knowledge differed considerablyby level of education; however, Attitude differed significantly according to gender and educational level. Correlations between the knowledge, attitude, behavioral behavioural, PHQ-4 and the psychological harm score shows that the variables "attitude, behavioural and Psychological harm" are significantly correlated with the PHQ-4 score, the higher the latter are the greater the last is high.In addition, the "Knowledge" variable is also significantly correlated. The greater the knowledge, the smaller the PHQ-4 score.
\end{abstract}

Conclusion: The covid-19 pandemic is a public health problem

Keywords:Covid-19; Morocco; Knowledge, Attitude; PHQ-4

\section{Background}

The COVID-19 outbreak has been rapidly transmitted and aroused enormous attention globally and which was originated from a wet market in Wuhan, Hubei province, China in early December $2019^{1}$. The outbreak caused

\section{Corresponding Author:}

\section{Soumaia HMIMOU}

Ibn Tofail University, Faculty of Science, Kenitra, Morocco, e-mail: Soumaia.hmimou@uit.ac.ma by SARS-CoV-2 was officially labelled a pandemic on March $12^{\text {th }}, 2020$ by Word Health Organization. Due to the disease being transmitted via close contact between persons, extreme social distancing measures have been used to curb its spread.

The Moroccan health authorities announce the country's first novel coronavirus case: A Moroccan man arrived from Italy in February, importing the virus. The Moroccan government reacted decisively to the threat of COVID-19 pandemic, declared a state of emergency, and imposed a strict one-month curfew on 20 March 
and extended it until 20 May 2020 before proceeding to the post-lockdown period. Epidemics and pandemics are a periodic phenomenon ${ }^{2}$.People in the community face several challenges during such periods. Lack of awareness often leads to an unconcerned attitude, which may adversely affect the preparedness to meet these challenges. Impacts of these epidemics and pandemics are often intense, which may adversely affect the mental well-being of a given population. The fear and anxiety related to epidemics and pandemics also influence the behaviour of people in the community. Few published studies have examined the mental health impacts of COVID-19 and mandatory lockdown contextual factors.

An Italian study found that lower self-discipline and perceptions of the lockdown measures as a limitation on personal freedom, were related to higher stress and a greater likelihood of violating governmental social isolation rules ${ }^{3}$. Also, in Italy, another study explores the role of psychological flexibility and its inverse, inflexibility in moderating the effects of the pandemic and lockdown context of mental health outcomes ${ }^{4}$. A study reports that having a family member infected with COVID-19 is related to higher anxiety ${ }^{5}$. Further studies mentioned that being an informal (e.g., parent) or formal (e.g., healthcare worker) caregiver, or a victim of domestic violence, are strong risk factors for adverse mental health outcomes during lockdown $n^{6,7,8,9}$. Furthermore, other studies showed that limited social capital decreased income during the pandemic or being a refugee or an undocumented migrant are associated with greater negative mental health outcomes ${ }^{8}$. Lastly, some study reports that older and younger people report more adverse mental health impacts from lockdown-related socializing restrictions (e.g., unable to receive visitors if living alone or hospitalized, and closure of schools and entertainment facilities) ${ }^{10,8,11}$.

\section{Materials and Methods}

This cross-sectional study was conducted in Morocco and was administered to a sample of 702 respondents. The subject was assessed using a questionnaire containing the following information: Personal demographic characteristics (age, gender, educational qualification and working status); knowledge and awareness of COVID-19 outbreak (Will you be cured if you are affected by COVID? Does all infected cases result in death? What are your personal measures against the outbreak? Using a mask, Hand washing, Avoiding indoor and crowded places, others ); Attitude towards COVID19outbreak (Deliberately cancelled or postponed social event, such as weeding ceremony, travelling, meeting friends, Taken time off work, Reducing the amount of time going outside, Reducing the amount of using public transport, Kept away from crowded places); Behavioral change in relation to COVID-19 outbreak (Deliberately cancelled or postponed social event, such as weeding ceremony, travelling, meeting fiends, Taken time off work,Reducing the amount of time going outside, Reducing the amount of using public transport, Kept away from crowded places); Patient Health Questionnaire (PHQ-4) screening questions for anxiety and depression (Feeling nervous, anxious our edge? Not being able to stop or control worrying?

Little interest or pleasure in doing things? Feeling down, depressed or hopeless?), and finally a questionnaire related to people at risk of psychological harm from social isolation during the COVID-19 pandemic (Do you live alone, Are you unemployed or have you lost your income during the pandemic, Are you a person with caretaking responsibilities, including childcare during extended school closures, Are you addicting to drugs or alcohol, Are you suffering from domestic violence, which is likely to be made worse with quarantine).

\section{Statistical Analysis}

The responses should be coded as follows:

Not at all, scored at 0

Several days, scored at 1

More than half the days, scored at 2

Nearly every day, scored at 3

Add the scores for each question together to give a possible total scorefrom 0 to 12 , with categories of psychological distress being:

- Scores 0-2= None

- Scores 3-5 = Mild 
- Scores 6-8 = Moderate

- Scores 9-12= Severe

- Anxiety subscale $=$ Sum of items 1 and 2 (score range 0 to 6 )

- Depression subscale $=$ Sum of items 3 and 4 (score range 0 to 6 )

The Data collected was entered in excel sheet and was analysed using SPSS, P value $>0,05$ was considered statistically significant.

Descriptive were calculated for statistics sociodemographic characteristics, knowledge and awareness of COVID-19 outbreak, Attitude towards COVID-19 outbreak, Behavioral change in relation to COVID-19 outbreak, Patient Health Questionnaire (PHQ-4) screening questions for anxiety and depression and a questionnaire related to people at risk of psychological harm from social isolation during the COVID-19 pandemic, Percentages of response were calculated according to the number of respondents per response with respect to the number of total responses of a question.

One-way ANOVAwas used to find the association of knowledge, attitudes and behavioral change, Patient Health Questionnaire (PHQ-4)and people at risk of psychological harm from social isolation towards COVID-19 in relation to different age groups and different literacy rate levels,test $t$ student was used to find the association of items in relation to gender and Occupational status, and we used Pearson Correlation to find the correlation between the 5 items.

\section{Results}

702 participants responded to the survey. The descriptive analysis of the database showed thatthe majority of respondents were male $(69.3 \%)$, aged 20 to 30 years $(46.15 \%)$, with university diploma $(61.25 \%)$ and employed (63.53\%).Of the respondents $98 \%$ had heard about COVID-19 outbreak whereas only $4.27 \%$ doesn't believe that the outbreak is serious.

However 94.59\% knew that COVID-19 outbreak was caused by a virus whereas $28.63 \%$ think that the disease is fatal. $64.39 \%$ reported that the disease is preventable whereas only $10.97 \%$ though that the disease is not contagious. Altogether $54.70 \%$ felt that Moroccan government has taken enough steps to eradicate the disease.

Regarding behavior change in relation to COVID-19, $70.80 \%$ (497) of the respondents had not cancelled or postponed any social event, $71.08 \%$ (499) had taken time off work and $90.3 \%$ (632) had reduced the amount of time going outside.

However, $85.75 \%$ (602) had reduced the use of public transport and 66.24\% (465) had kept away from crowded places. Concerning the measures taken by respondents against the outbreak, we found that $86.18 \%$ (605) used mask, 99.72\% (700) washed hands, 65.53\% (460) avoided indoor and crowded places, and 98.29\% (690) were overly worried so they increased the amount of cleaning or disinfecting things that might be touched such as door knobs or hard surfaces.

For the questionnaire related to people at risk of psychological harm from social isolation, $53.70 \%$ live alone, $71.08 \%$ unemployed or have you lost your income during the pandemic, $30.70 \%$ are a person with caretaking responsibilities, including childcare and $57.55 \%$ suffering from domestic violence, and $43.20 \%$ of participant are a severe psychological distress.

The results of our study show that the level of education differed significantly in knowledge among respondents at $\mathrm{p}=0.004$ (Least significant difference= 0.34).Attitude differed significantly according to gender and educational level. 
Table1: Association of knowledge, attitude, behavior, psychological harm from social isolation and PHQ-4 with gender using Students $t$ test.

\begin{tabular}{|c|c|c|c|c|c|c|}
\hline & Gender & Effectif & Mean & $\begin{array}{l}\text { Standard } \\
\text { Deviation }\end{array}$ & $\begin{array}{c}\text { Standard } \\
\text { Error }\end{array}$ & $P$ value \\
\hline \multirow{3}{*}{ Knowledge score } & Female & 210 & 5,57 & 0,744 & \multirow{2}{*}{0,051} & \multirow{3}{*}{0,920} \\
\hline & Male & 492 & 5,57 & 0,803 & & \\
\hline & Total & 702 & - & - & & \\
\hline \multirow{3}{*}{ Attitude score } & Female & 210 & 6,50 & 0,581 & \multirow{2}{*}{0,040} & \multirow{3}{*}{$0,002 *$} \\
\hline & Male & 492 & 6,29 & 0,847 & & \\
\hline & Total & 702 & - & - & - & \\
\hline \multirow{3}{*}{ Behavioral score } & Female & 210 & 3,61 & 1,294 & \multirow{2}{*}{0,089} & \multirow{3}{*}{$0,015^{*}$} \\
\hline & Male & 492 & 3,34 & 1,381 & & \\
\hline & Total & 702 & - & - & - & \\
\hline \multirow{3}{*}{ PHQ-4 score } & Female & 210 & 7,84 & 3,216 & \multirow{2}{*}{0,222} & \multirow{3}{*}{$0,001^{*}$} \\
\hline & Male & 492 & 6,84 & 3,691 & & \\
\hline & Total & 702 & - & - & - & \\
\hline \multirow{3}{*}{ Psychological score } & Female & 210 & 2,77 & 1,651 & \multirow{2}{*}{0,114} & \multirow{3}{*}{0,142} \\
\hline & Male & 492 & 2,56 & 1,692 & & \\
\hline & Total & 702 & - & - & - & \\
\hline
\end{tabular}

*Significant at $\mathrm{p}<0.05$

Table2: Association of knowledge, attitude, behavior, psychological harm from social isolation and PHQ-4 with age group using one way ANOVA

\begin{tabular}{|c|c|c|c|c|c|c|c|}
\hline & Age group & Effectif & Mean & $\begin{array}{l}\text { Standard } \\
\text { Deviation }\end{array}$ & $\begin{array}{c}\text { Standard } \\
\text { Error }\end{array}$ & $P$ value & $\begin{array}{l}\text { Least } \\
\text { significant } \\
\text { difference }\end{array}$ \\
\hline \multirow{6}{*}{ Knowledge score } & $20-30$ & 325 & 5,62 & 0,806 & 0,045 & \multirow{6}{*}{0,608} & \multirow{6}{*}{ - } \\
\hline & $30-40$ & 180 & 5,52 & 0,794 & 0,059 & & \\
\hline & $40-50$ & 113 & 5,57 & 0,789 & 0,074 & & \\
\hline & $50-60$ & 70 & 5,51 & 0,654 & 0,078 & & \\
\hline & $>60$ & 14 & 5,43 & 0,756 & 0,202 & & \\
\hline & Total & 702 & - & - & - & & \\
\hline \multirow{6}{*}{ Attitude score } & $20-30$ & 325 & 6,34 & 0,795 & 0,044 & \multirow{6}{*}{0,853} & \multirow{6}{*}{-} \\
\hline & $30-40$ & 180 & 6,37 & 0,777 & 0,058 & & \\
\hline & $40-50$ & 113 & 6,31 & 0,846 & 0,080 & & \\
\hline & $50-60$ & 70 & 6,43 & 0,672 & 0,080 & & \\
\hline & $>60$ & 14 & 6,43 & 0,514 & 0,137 & & \\
\hline & Total & 702 & - & - & - & & \\
\hline
\end{tabular}


Medico-legal Update, July-September 2021, Vol.21, No. 3

Cont... Table2: Association of knowledge, attitude, behavior, psychological harm from social isolation and PHQ-4 with age group using one way ANOVA

\begin{tabular}{|c|c|c|c|c|c|c|c|}
\hline \multirow{6}{*}{ Behavioral score } & $20-30$ & 325 & 3,80 & 1,068 & 0,059 & \multirow{6}{*}{$0,000 *$} & \multirow{6}{*}{0.18} \\
\hline & $30-40$ & 180 & 3,07 & 1,517 & 0,113 & & \\
\hline & $40-50$ & 113 & 2,96 & 1,543 & 0,145 & & \\
\hline & $50-60$ & 70 & 3,39 & 1,300 & 0,155 & & \\
\hline & $>60$ & 14 & 3,07 & 1,685 & 0,450 & & \\
\hline & Total & 702 & - & - & - & & \\
\hline \multirow{6}{*}{ PHQ-4 score } & $20-30$ & 325 & 7,24 & 3,638 & 0,202 & \multirow{6}{*}{$0,024 *$} & \multirow{6}{*}{0.14} \\
\hline & $30-40$ & 180 & 6,67 & 3,575 & 0,266 & & \\
\hline & $40-50$ & 113 & 6,85 & 3,556 & 0,335 & & \\
\hline & $50-60$ & 70 & 8,26 & 3,238 & 0,387 & & \\
\hline & $>60$ & 14 & 7,71 & 3,268 & 0,873 & & \\
\hline & Total & 702 & - & - & - & & \\
\hline \multirow{6}{*}{$\begin{array}{l}\text { Psychological } \\
\text { score }\end{array}$} & $20-30$ & 325 & 2,88 & 1,390 & 0,077 & \multirow{6}{*}{$0,001 *$} & \multirow{6}{*}{0.19} \\
\hline & $30-40$ & 180 & 2,36 & 1,839 & 0,137 & & \\
\hline & $40-50$ & 113 & 2,29 & 1,869 & 0,176 & & \\
\hline & $50-60$ & 70 & 2,73 & 1,903 & 0,227 & & \\
\hline & $>60$ & 14 & 2,21 & 2,119 & 0,566 & & \\
\hline & Total & 702 & - & - & - & & \\
\hline
\end{tabular}

*significant at $\mathrm{p}<0.05$

Table 3: Association of knowledge, attitude, behavior, psychological harm from social isolation and PHQ-4 with occupational status using Students $t$ test

\begin{tabular}{|c|c|c|c|c|c|c|}
\hline & Occupational status & Effectif & Mean & $\begin{array}{l}\text { Standard } \\
\text { Deviation }\end{array}$ & $\begin{array}{c}\text { Standard } \\
\text { Error }\end{array}$ & $P$ value \\
\hline \multirow{3}{*}{ Knowledge score } & No-working & 256 & 5,58 & 0,783 & \multirow{2}{*}{0,049} & \multirow{3}{*}{0,783} \\
\hline & Working & 446 & 5,57 & 0,787 & & \\
\hline & Total & 702 & - & - & - & \\
\hline \multirow{3}{*}{ Attitude score } & No-working & 256 & 6,36 & 0,699 & \multirow[t]{2}{*}{0,044} & \multirow{3}{*}{0,955} \\
\hline & Working & 446 & 5,57 & 0,787 & & \\
\hline & Total & 702 & - & - & - & \\
\hline \multirow{3}{*}{ Behavioral score } & No-working & 256 & 6,36 & 0,699 & \multirow{2}{*}{0,044} & \multirow{3}{*}{$0,000 *$} \\
\hline & Working & 446 & 6,35 & 0,826 & & \\
\hline & Total & 702 & - & - & - & \\
\hline \multirow{3}{*}{ PHQ-4 score } & No-working & 256 & 3,91 & 0,811 & \multirow{2}{*}{0,051} & \multirow{3}{*}{$0,000 *$} \\
\hline & Working & 446 & 3,15 & 1,525 & & \\
\hline & Total & 702 & - & - & - & \\
\hline \multirow{3}{*}{ Psychological score } & No-working & 256 & 3,04 & 1,407 & \multirow{2}{*}{0,088} & \multirow{3}{*}{$0,000 *$} \\
\hline & Working & 446 & 2,38 & 1,777 & & \\
\hline & Total & 702 & - & - & - & \\
\hline
\end{tabular}

*significant at $\mathrm{p}<0.05$ 
Table 4: Association of knowledge, attitude, behavior, psychological harm from social isolation and PHQ-4 with educational level using one way ANOVA.

\begin{tabular}{|c|c|c|c|c|c|c|c|}
\hline & Educational level & Effectif & Mean & $\begin{array}{l}\text { Standard } \\
\text { Deviation }\end{array}$ & $\begin{array}{c}\text { Standard } \\
\text { Error }\end{array}$ & P value & $\begin{array}{c}\text { Least } \\
\text { significant } \\
\text { difference }\end{array}$ \\
\hline \multirow{6}{*}{ Knowledge score } & Illiterate & 6 & 5,00 & 0,000 & 0,000 & \multirow{6}{*}{$0,004 *$} & \multirow{6}{*}{0.34} \\
\hline & Primary education & 10 & 5,30 & 0,823 & 0,260 & & \\
\hline & Middle & 12 & 5,58 & 0,793 & 0,229 & & \\
\hline & High school education & 244 & 5,45 & 0,807 & 0,052 & & \\
\hline & University diploma & 430 & 5,66 & 0,765 & 0,037 & & \\
\hline & Total & 702 & - & - & - & & \\
\hline \multirow{6}{*}{ Attitude score } & Illiterate & 6 & 7,00 & 0,000 & 0,000 & \multirow{6}{*}{$0,004 *$} & \multirow{6}{*}{0.15} \\
\hline & Primary education & 10 & 6,40 & 0,516 & 0,163 & & \\
\hline & Middle & 12 & 6,33 & 0,492 & 0,142 & & \\
\hline & High school education & 244 & 6,21 & 1,068 & 0,068 & & \\
\hline & University diploma & 430 & 6,42 & 0,565 & 0,027 & & \\
\hline & Total & 702 & - & - & - & & \\
\hline \multirow{6}{*}{ Behavioral score } & Illiterate & 6 & 0,50 & 1,225 & 0,500 & \multirow{6}{*}{$0,000^{*}$} & \multirow{6}{*}{0.42} \\
\hline & Primary education & 10 & 1,50 & 1,080 & 0,342 & & \\
\hline & Middle & 12 & 2,42 & 1,505 & 0,434 & & \\
\hline & High school education & 244 & 2,38 & 1,550 & 0,099 & & \\
\hline & University diploma & 430 & 4,13 & 0,463 & 0,022 & & \\
\hline & Total & 702 & - & - & - & & \\
\hline \multirow{6}{*}{ PHQ-4 score } & Illiterate & 6 & 6,33 & 0,816 & 0,333 & \multirow{6}{*}{$0,000^{*}$} & \multirow{6}{*}{0.25} \\
\hline & Primary education & 10 & 5,10 & 2,601 & 0,823 & & \\
\hline & Middle & 12 & 7,33 & 3,312 & 0,956 & & \\
\hline & High school education & 244 & 4,58 & 3,434 & 0,220 & & \\
\hline & University diploma & 430 & 8,65 & 2,786 & 0,134 & & \\
\hline & Total & 702 & - & - & - & & \\
\hline \multirow{6}{*}{ Psychological score } & Illiterate & 6 & 0,17 & 0,408 & 0,167 & \multirow{6}{*}{$0,000^{*}$} & \multirow{6}{*}{0.16} \\
\hline & Primary education & 10 & 0,60 & 1,578 & 0,499 & & \\
\hline & Middle & 12 & 1,92 & 2,314 & 0,668 & & \\
\hline & High school education & 244 & 1,15 & 1,048 & 0,067 & & \\
\hline & University diploma & 430 & 3,56 & 1,219 & 0,059 & & \\
\hline & Total & 702 & - & - & - & & \\
\hline
\end{tabular}

*significant at $\mathrm{p}<0.05$ 
Table 5: Correlation between knowledge, attitude, behavior, psychological harm from social isolation and PHQ-4 using Pearson correlation test

\begin{tabular}{|c|c|c|c|c|c|}
\hline & Knowledge score & Attitude score & PHQ-4 score & Psychological score & Behavioral score \\
\hline Knowledge score & - & $-0,566^{* *}$ & $-0,284^{* *}$ & $0,558^{* *}$ & $0,362^{* *}$ \\
\hline Attitude score & $-0,566^{* *}$ & - & $0,637^{* *}$ & $-0,342^{* *}$ & $-0,366^{* *}$ \\
\hline PHQ-4 score & $-0,284^{* *}$ & $0,637^{* *}$ & - & $0,195^{* *}$ & $0,168^{* *}$ \\
\hline Psychological score & $0,558^{* *}$ & $-0,342^{* *}$ & $0,195^{* *}$ & - & $0,781^{* *}$ \\
\hline Behavioral score & $0,362^{* *}$ & $-0,366^{* *}$ & $0,168^{* *}$ & $0,781^{* *}$ & - \\
\hline
\end{tabular}

** Correlation is significant at the 0.01 level (2-tailed)

The table 5 of correlations between the knowledge, attitude, behavioral, PHQ-4 and psychological harm score shows that the variables "attitude, behavioral and Psychological harm" are significantly correlated with the PHQ-4 score, the higher the latter are the greater the last is high.In addition, the "Knowledge" variable is also significantly correlated. The greater the knowledge, the smaller the PHQ-4 score.

\section{Discussion}

Epidemics and pandemics are tough periodic phenomena in which a given population community face a several changes in their wellbeing, mental health and behaviors.

In order to control the outbreak COVID-19 infection, health authorities and governments all around the worldhaveemployed measures, Chinese health authorities was the first country have employed rapid public health measures, including intensive surveillance, epidemiological investigation and closure of markets on January $1,2020^{12}$. To discuss our findings, published articles concerning mental health related to previous outbreaks and COVID-19 outbreak have been considered.

In 16 Mars 2020, Moroccan government and health authorities has proceeded to lock down cities and isolated people in their houses. This new way of living have an immense impact in all the living area especially in the mental health of the Moroccan community.

This study attempted to evaluate the awareness, attitude, anxiety and perceived mental healthcare needs in the society.Isolation may be protective and preventive in many circumstances, previous experiences mentioned an increase of mental distress during this events have been described ${ }^{13}$.

$69,3 \%$ of the respondents were male, half of responses came from persons aged between 20-30 years. Almost all the answers knows the origins of COVID-19, aware of the situation. $14,5 \%$ do not have any idea if is the disease fatal. More than the half of respondents were satisfied with measures taken by the government.

In the previous outbreak situations, it is necessary to create a health education awareness during pandemics: epidemics for effective prevention of disease spread ${ }^{14}$. Our findings showed that the Moroccan population were aware about the danger of COVID-10, for that, more the three quarter of the respondents used masks, hand washing, avoiding crowded places, ceremonies, events, etc. This recommendation was already described in the literature in previous outbreaks ${ }^{15,16}$. The use of masks and sanitizers increased since the onset of COVID-19 17 .

This level of awareness may be affected by the educational level; our results showed that just $0,85 \%$ of 
the respondents were illiterate, $1,43 \%$ have a primary education and 1,71\% have middle level education. 97\% were graduated from high school or have a university diploma.

Working people represented 63, 25\%. Previous studies showed that education level, employment and age have an influence on knowledge ${ }^{18}$.

Our study showed that most people reduced the amount of using public transportation and kept away from crowded places, despite these attitudes, many people ignore the importance of social distancing and isolation, so they had not cancelled or postpones any social event, and had not taken any time off work, Our findings are approximatively similar to James Rubin et al study ${ }^{19}$.

The current situationcause mental health problems such as stress, anxiety, depressive symptoms, insomnia, anger and ear ${ }^{14}$. Our results demonstrated than 35, 9\% of the respondents showed a score of two (PHQ4) for anxiety and feeling nervous. In the other hand, 33\% have no control to stop worrying, $43 \%$ are feeling down depressed nearly every day (score 3 ). These resultsjoined previous studies about the effect of outbreaks in mental health ${ }^{20,21}$.

In addition, to live alone could exercise a huge impact of the mental health; our results showed that $53.7 \%$ of the participants live alone. Loneliness is a subject unpleasant effect on mental and physical health could lead to premature death and rates comparable to obesity and smoking 22,23 .

\section{Conclusion}

The Covid-19 pandemic had a negative impact on the mental health of the population during the period of containment.

Loneliness or more almost the fact of going through containment alone is a subject that has unpleasant effects on the mental and physical health of the population.

Ethical Clearance: The procedures were carried outin accordance with the recommendations of the internalEthics Committee of the Ibn Tofail University Kenitra.This procedure were examined and approved by the Committee.

Availability of data and materials: The datasets used and analyzed during the current study are available from the corresponding author on reasonable request.

Competing interests: The authors declare that they have no competing interests

Funding: This work is funded by the PPR-BMokhtari-FS-UIT-Kénitra project.

Authors' contributions: All authors contributed equally, all authors read and approved the final manuscript.

Acknowledgements: The authors would like to thank all the participants in our study. In addition, we express our heartfelt respect to all healthcare workers who are fighting the COVID-19 pandemic on the front line.

\section{References}

1. Lu H, Stratton CW, Tang YW. (2020) Outbreak of pneumonia of unknown etiology in Wuhan, China: The mystery and the miracle. Journal of medical virology. 92(4):401-402

2. Deblina R, Sarvodaya T, Sujita Kumar K, Nivedita S, Sudhir Kumar V, Vikas K. (2020). Study of knowledge, attitude, anxiety \& perceived mental healthcare need in Indian population during COVID-19 pandemic. Asian Journal of Psychiatry. 51: 102083 .

3. Flesia, L, Fietta, V, Colicino, E, Segatto, B, \& Monaro, M. (2020). Stable psychological traits predict perceived stress related to the COVID-19 outbreak. PsyArXiv. https://doi.org/10.31234/osf. io/yb2h8

4. Pakenham K.I., Landi G., Boccolini G., Furlani A., Grandi S. \& Tossani E. (2020). The Moderating Roles of Psychological Flexibility and Inflexibility on the Mental Health Impacts of COVID-19Pandemic and Lockdown in Italy, Journal of Contextual Behavioral Science. 17: 109-17.

5. Cao, Cao, W., Fang, Z., Hou, G., Han, M., Xu, X., Dong, J., \& Zheng, J. (2020). The psychological impact of the COVID-19 epidemic on college 
students in China. Psychiatry Research. 287:112934

6. Bradbury Jones, C., \& Isham, L. (2020). The pandemic paradox: the consequences of COVID19 on domestic violence. Journal of Clinical Nursing. https://doi.org/10.1111/jocn.15296

7. Pappa, S., Ntella, V., Giannakas, T., Giannakoulis, V. G., Papoutsi, E., \& Katsaounou, P. (2020). Prevalence of depression, anxiety, and insomnia among healthcare workers during the COVID- 19 pandemic: A systematic review and meta-analysis. Brain, Behavior, and Immunity. Aug; 88:901-907.

8. Razai, M., Oakeshott, P., Kankam, H., Galea, S., \& Stokes-Lampard, H. (2020). Mitigating the psychological effects of social isolation during the covid-19 pandemic. May 21;369:m1904.

9. Vindegaard, N., \& Benros, M. E. (2020). COVID-19 pandemic and mental health consequences: systematic review of the current evidence. Brain, Behavior, and Immunity.Oct; 89:531-542

10. Girdhar, R., Srivastava, V., \& Sethi, S. (2020). Managing mental health issues among elderly during COVID-19 pandemic. Journal of Geriatric Care and Research, 7(1), 29-32.

11. Wang, G., Zhang, Y., Zhao, J., Zhang, J., \& Jiang, F. (2020). Mitigate the effects of home confinement on children during the COVID-19 outbreak. The Lancet, 395(10228), 945-947.

12. Chen, N., Zhou, M., Dong, X.et al. (2020). Epidemiological and clinical characteristics of 99 cases of 2019 novel coronavirus pneumonia in Wuhan, China: A descriptive study. The Lancet, 15;395(10223):507-513

13. . Fagan, J., Galea, S., Ahern, J., Bonner, S., \& Vlahov, D. (2003). Relationship of self-reported asthma severity and urgent health care utilization to psychological sequelae of the September 11, 2001 terrorist attacks on the World Trade Center among New York City area residents. Psychosomatic Medicine. 65, 993-996.

14. Jones, N. M., Thompson, R. R., Dunkel Schetter, C., \& Silver,R. C. (2017). Distress and rumor exposure on social mediaduring a campus lockdown.
Proceedings of the NationalAcademy of Sciences of the United States of America, 114,11663-11668

15. Blendon RJ, Koonin LM, Benson JM, et al. (2008) Public response to community mitigation measures for pandemic influenza. Emerg Infect Dis. 14(5):778-86

16. McCloskey, B., Zumla, A., Ippolito, G., Blumberg, L., Arbon, P., Cicero, A., Endericks, T., Lim, P.L., Borodina, M., 2020. Mass gathering events and reducing further global spread of COVID-19: a political and public health dilemma. The Lancet.395(10230): 1096-1099.

17. S. Feng, C. Shen, N. Xia, W. Song, M. Fan, B.J. Cowling Rational use of face masks in the COVID-19 pandemic Lancet Respir Med, 8 (5) (2020), pp. 434-436,

18. Farid-ul-Hasnain S, Johansson E, Krantz G (2009) What do young adults know about the HIV/AIDS epidemic? Findings from a population based study in Karachi, Pakistan. BMC Infectious Diseases 9, 38 (2009)

19. Rubin GJ, Amlôt R, Page L, Wessely S (2009) Public perceptions, anxiety, and behavior change in relation to the swine flu outbreak: cross sectional telephone survey. BMJ 339: 2651.

20. Purgato, M., Gastaldon, C., Papola, D., van Ommeren, M.,Barbui, C., \& Tol, W. A. (2018). Psychological therapiesfor the treatment of mental disorders in low- and middleincome countries affected by humanitarian crises. CochraneDatabase of Systematic Reviews, 5;7(7):CD011849.

21. Kang, L., Li, Y., Hu, S., Chen, M et al. (2020). The mental health of medical workers in Wuhan, China dealing with the 2019 novel coronavirus. The Lancet Psychiatry7(3):e14.

22. Holt-Lunstad J, Smith TB, Baker M, Harris T, Stephenson D. Loneliness and social isolation as risk factors for mortality: a meta-analytic review. Perspect Psychol Sci 2015; 10(2):227-237

23. Courtin E, Knapp M. (2017). Social isolation, loneliness and health in old age: a scoping review. Health Soc Care Community. 25(3):799-812 